\title{
Preparation of Molecularly Imprinted Polymers Using Photocross-linkable Polyphosphazene and Selective Rebinding of Amino Acids
}

\author{
Seung Cheol Lee and Ji Young Chang* \\ Department of Materials Science and Engineering, Seoul National University, Seoul 151-744, Korea
}

Received October 16, 2008; Revised November 25, 2008; Accepted November 27, 2008

\begin{abstract}
A photocrosslinkable polyphosphazene was used for molecular imprinting. We synthesized polyphosphazene (3) having urea groups for complexation with $N$-carbobenzyloxyglycin (Z-Gly-OH, template) and chalcone groups for cross-linking reaction. As substituents, 4-hydroxychalcone (1) and $N$-(4-hydroxyphenyl)- $N{ }^{\prime}-$ ethylurea (2) were prepared. Choloro groups of poly(dichlorophosphazene) were replaced by the sequential treatment with sodium salts of compounds $\mathbf{1}$ and $\mathbf{2}$, and trifluoroethanol. The template molecule was complexed with the urea groups on the polymer chains via hydrogen bonding. A thin polymer film was prepared by casting a solution of the complex of polymer 3 and the template in dimethylformamide on a quartz cell and irradiated with 365 nm UV light to yield a cross-linked film with a thickness of about $16 \mu \mathrm{m}$. The template molecules in the film were removed by Soxhlet extraction with methanol/acetic acid. The control polymer film was prepared in the same manner for the preparation of the imprinted polymer film, except that the template and triethylamine were omitted. In the rebinding test, the imprinted film exhibited much higher recognition ability for the template than the control polymer. We also investigated the specific recognition ability of the imprinted polymer for the template and its structural analogues. The rebinding tests were conducted using Z-Glu-OH, Z-Asp $\left(\mathrm{O}^{t} \mathrm{Bu}\right)-\mathrm{OH}$, and Z-GluOMe. The imprinted film showed higher specific recognition ability for the template and the lowest response for $\mathrm{Z}-\mathrm{Asp}\left(\mathrm{O}^{\mathrm{t}} \mathrm{Bu}\right)-\mathrm{OH}$.
\end{abstract}

Keywords: molecular imprinting, polyphosphazene, photocross-linking, amino acid.

\section{Introduction}

There has been great interest in materials that show ability to selectively recognize specific molecules since they have potential uses in applications such as chemical sensors, stationary phases for high performance chromatography, catalysts and membranes for separating toxic chemicals. Molecular imprinting constitutes a valuable method of preparing such materials. ${ }^{1-6}$ Molecularly imprinted polymers are generally prepared by the polymerization of a complex of a target molecule (template) with a functional vinyl monomer in the presence of a cross-linker. ${ }^{7,8}$ Subsequent removal of the template from the matrix generates a cavity, which can recognize the template. The matrix should have a rigid structure to prevent structural changes of the cavity occurring by relaxation or diffusion of the matrix molecules. To obtain rigid structures, an excess of cross-linking agent is used during polymerization, but which sometimes has an adverse effect on the interaction between the template and the matrix, resulting in low recognition capacity. Some other drawbacks of this approach include the difficulty of controlling

*Corresponding Author. E-mail: jichang@snu.ac.kr the cross-linking reaction and the lack of processibility of the resulting polymer.

We previously reported a molecularly imprinted thin film using an aromatic polyimide as the imprinted matrix. ${ }^{9,10}$ A polymer film was fabricated by casting a solution of poly(amic acid), prepared by condensation polymerization of an aromatic dianhydride and an aromatic diamine-template complex, on a substrate. Subsequent thermal imidization and extraction of the template resulted in the imprinted polyimide film. The aromatic polyimide was insoluble in common organic solvents due to the strong interactions between the polymer chains and showed a satisfactory result as a noncross-linked imprinted matrix.

In the present work, we explored the use of a flexible linear polymer for molecular imprinting. Our approach is schematically shown in Figure 1. The linear polymer is photoreactive and has functionality designed for complexation with template molecules. In the first step, the template molecule is complexed with the functional side groups on the flexible polymer chains via noncovalent bondings. The resulting complex is further polymerized by photoirradiation, leading to a rigid network structure. The template molecule is finally removed from the polymer matrix to form a cavity. 


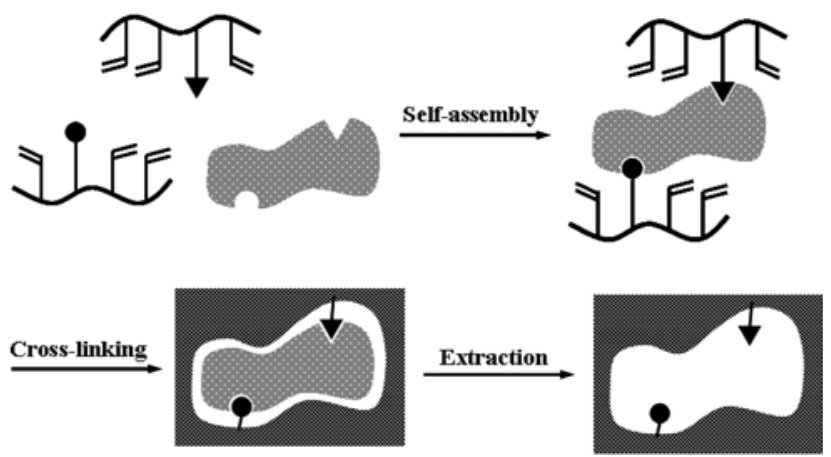

Figure 1. Molecular imprinting process using a linear functional polymer.

Polyphosphazenes are an interesting class of polymers because of their ease of functionalization as well as their physicochemical stability. Various side groups can be attached onto the $-\mathrm{P}=\mathrm{N}$ - polymer backbone by a substitution reaction with poly(dichlorophosphazene), which allows the polymers to exhibit a wide range of properties. ${ }^{11-13}$ We introduced a urea functionality into the polymer backbone for complexation with the template. A urea is known to form stable hydrogen bondings with various proton acceptors. ${ }^{14-16}$ We chose a chalcone as a cross-linking group. A chalcone is known to form a dimer by [2+2] addition reaction when exposed to UV light. ${ }^{17-20}$ We were able to obtain the molecularly imprinted thin film by casting a solution of the polymer complex on a substrate, and subsequent cross-linking and extraction.

\section{Experimental}

Materials and Instruments. Hexachlorocyclotriphosphazene $\left(\mathrm{NPCl}_{2}\right)_{3}(99 \%)$, acetophenone $(97 \%)$, 4-hydroxybenzaldehyde (99+\%), 4-aminophenol (99\%), 2,2,2-trifluoroethanol $(99+\%)$, triethylamine $(99+\%$, TEA), $N$-carbobenzyloxyglycine (99\%, Z-Gly-OH), $N$-(carbobenzyloxy)-Lglutamic acid (99\%, Z-Glu-OH) and sodium hydride (dry 95\%) were purchased from Aldrich (Chemical Co.). $N$-(carbobenzyloxy)-L-Aspartic acid 4-tert-butyl ester (99\%, Z-Asp $\left.\left(\mathrm{O}^{t} \mathrm{Bu}\right)-\mathrm{OH}\right)$ and $\mathrm{N}$-(carbobenzyloxy)-L-glutamic acid 1-methyl ester (99\%, Z-Glu-OMe) were purchased from Fluka. Tetrahydrofuran (THF) was dried over sodium metal and distilled. $N, N^{\prime}$-Dimethylformamide (DMF) and dimethyl sulfoxide (DMSO) were purchased from Junsei Chemical. Water and methanol were purchased from J. T. Baker (HPLC grade) and used as received. ${ }^{1} \mathrm{H}$ and ${ }^{31} \mathrm{P}$ nuclear magnetic resonance (NMR) spectra were measured by a Bruker Avance DPX-300 (300 MHz for ${ }^{1} \mathrm{H}$ NMR) spectrometer and a Bruker Avance DPX-500 (200 MHz for ${ }^{31} \mathrm{P}$ NMR) spectrometer. All chemical shifts were listed in ppm downfield from tetramethylsilane ( $\left.{ }^{1} \mathrm{H} \mathrm{NMR}\right)$ and phosphoric acid $\left({ }^{31} \mathrm{P} \mathrm{NMR}\right)$. The differential scanning calorimetry (DSC) measurements were performed by a TA modulated DSC Q10 at scanning rate of $5{ }^{\circ} \mathrm{C} / \mathrm{min}$. Reverse phase HPLC analysis was carried out using a M930 solvent delivery system, a RI750F refractive index detector (YOUNG LIN Instrument Co. Ltd., Korea), and a SUNFIRE C18 $5 \mu \mathrm{m}$ column from Waters. The eluent was $20 \%$ of phosphoric acid buffer $(0.01 \mathrm{M}, \mathrm{pH} 3.0)$ in methanol. For each analysis, $20 \mu \mathrm{L}$ of a sample was injected.

Synthesis of Linear Poly(dichlorophosphazene). Hexachlorocyclotriphosphazene was purified by recrystallization from $n$-hexane and sublimation at $55^{\circ} \mathrm{C}$ under vacuum. Hexachlorocyclotriphosphazene and a magnetic stirrer were put into a $50 \mathrm{~mL}$ ampule, which was dried under vacuum for $1 \mathrm{~h}$ and then sealed. The sealed ampule was placed in an oil bath at $250{ }^{\circ} \mathrm{C}$ with stirring. Polymerization was carried out until the viscous liquid in the ampule did not flow. The ampule was cooled down to room temperature and moved to the glove box filled with dry argon gas. The ampule was broken and poly(dichlorophosphazene) was recovered from the mixture by sublimation at $55^{\circ} \mathrm{C}$ under vacuum.

Synthesis of Chalcone Compound (1). Acetophenone (1.2 g, $10 \mathrm{mmol}$ ) and 4-hydroxybenzaldehyde (1.22 g, 10 $\mathrm{mmol})$ were dissolved in acetic acid $(150 \mathrm{~mL})$. Sulfuric acid $(5 \mathrm{~mL})$ was added to the solution and stirred overnight at room temperature. The reaction mixture was neutralized ( $5 \mathrm{~N}$ $\mathrm{NaOH}$ solution). After evaporation of the solvents, the product was isolated by column chromatography on silica gel (EA/ $n$-hexane $=1 / 1 \mathrm{v} / \mathrm{v}$ ) and further purified by recrystallization (EA/n-hexane). (yield : $0.20 \mathrm{~g}, 90 \%$ ).

${ }^{1} \mathrm{H}$ NMR (DMSO- $d_{6}$ ): $\delta 10.1$ (s, OH phenol, $\left.1 \mathrm{H}\right), 8.11-6.8$ (dd, $-\mathrm{CH}=\mathrm{CH}-, 2 \mathrm{H}), 7.8-7.5$ (m, aromatic, 9H). IR $\left(\mathrm{KBr}, \mathrm{cm}^{-1}\right)$ : 3250, 1651, 1599, 1510, 1349, 1285, 1219, 1168, 1041, 1022, 979, 834, 781, 725, 690, 661. Anal. Calcd. for $\mathrm{C}_{15} \mathrm{H}_{12} \mathrm{O}_{2}: \mathrm{C}$, 80.34; H, 5.39. Found: C, 80.25; H, 5.32.

Synthesis of Urea Compound (2). Ethyl isocyanate $(0.71 \mathrm{~g}$, $10 \mathrm{mmol}$ ) was added dropwise to a solution of 4-aminophenol $(1.09 \mathrm{~g}, 10 \mathrm{mmol})$ in THF $(100 \mathrm{~mL})$. The reaction mixture was stirred for $12 \mathrm{~h}$ at room temperature. The solvent was evaporated and the product was isolated by column chromatography on silica gel $(\mathrm{EA} / n$-hexane $=5 / 1 \mathrm{v} / \mathrm{v})$. (yield: $0.153 \mathrm{~g}, 85 \%)$.

${ }^{1} \mathrm{H}$ NMR (DMSO- $d_{6}$ ): $\delta 8.9$ (s, OH of phenol, $\left.1 \mathrm{H}\right), 8.0(\mathrm{~s}$, $\mathrm{NH}$ of aromatic-NH, $1 \mathrm{H}), 5.9\left(\mathrm{~s}, \mathrm{NH}\right.$ of $\left.\mathrm{CONHCH}_{2}, 1 \mathrm{H}\right)$, 7.1, $6.6(\mathrm{dd}, \mathrm{CH}$ of aromatic ring, $4 \mathrm{H}), 3.1\left(\mathrm{~m}, \mathrm{CH}_{2}, 2 \mathrm{H}\right)$, 1.0 (t, $\left.\mathrm{CH}_{3}, 3 \mathrm{H}\right)$. IR (KBr, cm $\left.{ }^{-1}\right): 3396,3348,3125,1664$, 1611, 1559, 1508, 1439, 1363, 1313, 1222, 833, 669. Anal. Calcd. for $\mathrm{C}_{9} \mathrm{H}_{12} \mathrm{~N}_{2} \mathrm{O}_{2}$ : C, 59.99; H, 6.71; N, 15.55. Found: C, 60.21; H, 6.68; N, 15.83.

Preparation of Polyphosphazene (3). A solution of compound $2(0.16 \mathrm{~g}, 0.9 \mathrm{mmol})$ in $20 \mathrm{~mL}$ of THF was added dropwise to a suspension of sodium hydride $(0.023 \mathrm{~g}, 0.9$ $\mathrm{mmol})$ in THF $(20 \mathrm{~mL})$ at room temperature. This sodium salt solution was added to a solution of poly(dichlorophosphazene) $(0.52 \mathrm{~g}, 9.0 \mathrm{mmol}$ of $\mathrm{Cl})$ in THF $(100 \mathrm{~mL})$ at room temperature and the mixture was stirred at reflux temperature for $24 \mathrm{~h}$. In a separate reaction, compound 1 (0.41 g, 1.8 
mmol) was added to a suspension of sodium hydride ( $0.046 \mathrm{~g}$, $1.8 \mathrm{mmol}$ ) in $100 \mathrm{~mL}$ of THF. This second sodium salt solution was added to the polyphosphazene solution at room temperature and the mixture was stirred at reflux temperature for $24 \mathrm{~h}$. Finally a solution of trifluoroethoxide prepared from 2,2,2-trifluoroethanol $(0.9 \mathrm{~g}, 9 \mathrm{mmol})$ and sodium hydride $(0.23 \mathrm{~g}, 9 \mathrm{mmol})$ in THF $(100 \mathrm{~mL})$ was added to the polyphosphazene solution at room temperature and the mixture was stirred at reflux temperature for $24 \mathrm{~h}$. The reaction mixture was cooled to room temperature, and the polymer was precipitated into water. The polymer was purified further by precipitations from THF into water, methanol, and $n$-hexane, and dried in vacuo to yield a rubbery solid (yield: $1.05 \mathrm{~g}$ ).

${ }^{1} \mathrm{H}$ NMR (DMSO- $d_{6}$ ): $\delta 8.3$ (br, NH of urea) 8.0-6.8 (br, $\mathrm{CH}=\mathrm{CH}$ of chalcone and $\mathrm{CH}$ of aromatic rings of urea and chalcone) 6.0 (br, $\mathrm{NH}$ of urea) $4.3\left(\mathrm{br},-\mathrm{CH}_{2} \mathrm{CF}_{3}\right) 3.0$ (br, $\mathrm{CH}_{2}$ of urea) $1.0\left(\mathrm{CH}_{3}\right.$ of urea). ${ }^{31} \mathrm{P}$ NMR (DMSO- $\left.d_{6}\right): \delta-11.6$, -13.9, -18.8. IR (KBr, cm$\left.{ }^{-1}\right): 3372,3066,2970,1667,1602$, 1508, 1418, 1285, 1166, 1084, 1017, 904, 836, 778, 722, 693, 655.

Preparation of Imprinted Polymer Film. Polyphosphazene 3 (40 mg), Z-Gly-OH (6.3 mg, $0.03 \mathrm{mmol}$ ), TEA (4 $\mathrm{mg}, 0.04 \mathrm{mmol})$ were dissolved in DMF $(2 \mathrm{~mL})$ and stirred for $30 \mathrm{~min}$. The solution was put into a quartz cell $(1.5 \mathrm{~cm} \times$ $1.5 \mathrm{~cm} \times 1.5 \mathrm{~cm})$ and dried in vacuo at $40{ }^{\circ} \mathrm{C}$ for $3 \mathrm{~h}$. The quartz cell was placed under a UV lamp $(365 \mathrm{~nm})$ for $3 \mathrm{~h}$. The cross-linked polymer film was pilled off from the quartz cell and washed with methanol. The template molecules in the polymer film were removed by Soxhlet extraction with $200 \mathrm{~mL}$ of a methanol/acetic acid mixture (9:1 v/v) for $24 \mathrm{~h}$ and $200 \mathrm{~mL}$ of methanol for $3 \mathrm{~h}$.

Preparation of Control Polymer Film. The control polymer film was prepared in the same manner for preparation of the imprinted polymer film, except that the template and TEA were omitted.

Rebinding Test. The imprinted film or the control film was added to a solution of the template in chloroform at various concentrations (1, 2 and $3 \mathrm{mM})$. After incubating for $24 \mathrm{~h}$ at $25{ }^{\circ} \mathrm{C}$, the polymer films were isolated by filtration and washed with chloroform. The filtrate was concentrated to dryness by evaporation of the solvent before HPLC analysis.

Selectivity Test. The imprinted film or the control film (20 mg) was added to a solution $(2 \mathrm{mM})$ of an analyte (listed in Figure 6) in chloroform $(10 \mathrm{~mL})$. After incubating for $24 \mathrm{~h}$, the polymer film was isolated by filtration and washed with chloroform. The filtrate was concentrated to dryness by evaporation of the solvent before HPLC analysis.

\section{Results and Discussion}

Synthesis of Functional Polyphosphazene. We synthesized polyphosphazene (3) having urea groups for complexation with $\mathrm{N}$-carbobenzyloxyglycin (Z-Gly-OH, template)

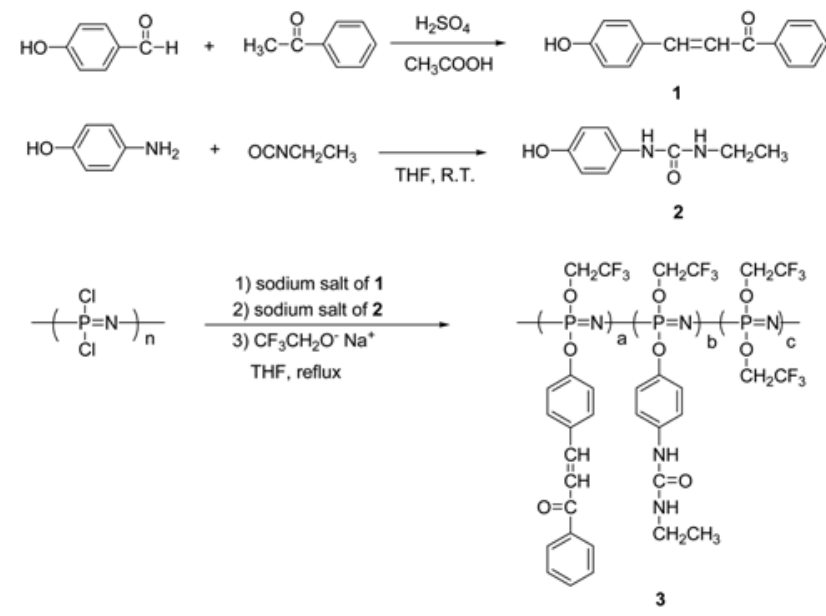

Scheme I. Synthetic route of functional polyphosphazene (3).

and chalcone groups for cross-linking reaction according to Scheme I. 4-Hydroxychalcone (1) was prepared by condensation reaction of acetophenone with 4-hydroxybenzaldehyde under acidic conditions. $N$-(4-Hydroxyphenyl)- $N$ 'ethylurea (2) was prepared by the reaction of 4-amino phenol with ethyl isocyanate in THF. Compounds $\mathbf{1}$ and $\mathbf{2}$ were converted to their sodium salts prior to reacting with poly (dichlorophosphazene), which was prepared by thermal polymerization of hexachlorocyclotriphosphazene at $250{ }^{\circ} \mathrm{C}$. Chloro groups of poly(dichlorophosphazene) were replaced by the sequential treatment with sodium salts of compounds $\mathbf{1}$ and $\mathbf{2}$, and trifluoroethanol.

Figure 2 shows the ${ }^{1} \mathrm{H}$ NMR spectrum of polymer 3 in DMSO- $d_{6}$. The peaks for N-H protons from urea units appeared at 8.4 and $6.0 \mathrm{ppm}$ and the peaks for ethyl protons from chalcone units at 3.0 and $1.0 \mathrm{ppm}$. The peak at $4.3 \mathrm{ppm}$ was assigned to methylene protons from trifluoroethoxy groups. The substitution ratio was determined based on the peak areas. The physical properties of the resulting polymers were influenced greatly by the composition of the substituents. The solubility of the polymers in common organic solvents decreased as the substitution ratio of the urea and chalcone units increased. We controlled the substitution ratio of urea/chalcone/trifluoroethanol to be 1:2:7 to make a flexible thin film. The number and weight molecular weights of the polymer determined by GPC with polystyrene standards were $1.17 \times 10^{6}$ and $2.84 \times 10^{6}$, respectively.

Complexation and Cross-Linking. We investigated complexation of the template (Z-Gly-OH) with the urea compound (2) by ${ }^{1} \mathrm{H}$ NMR spectroscopy. Compound 2 and ZGly-OH were dissolved in DMSO- $d_{6}$ containing 1.2 equivalent amount of triethylamine, and its ${ }^{1} \mathrm{H}$ NMR spectra were measured at various ratios of compound $\mathbf{2}$ to the template. In the ${ }^{1} \mathrm{H}$ NMR spectrum (Figure 3 ), the N-H proton peaks of the urea appeared at 8.0 and $5.9 \mathrm{ppm}$. As the concentration of the template increased, the N-H proton peaks were 


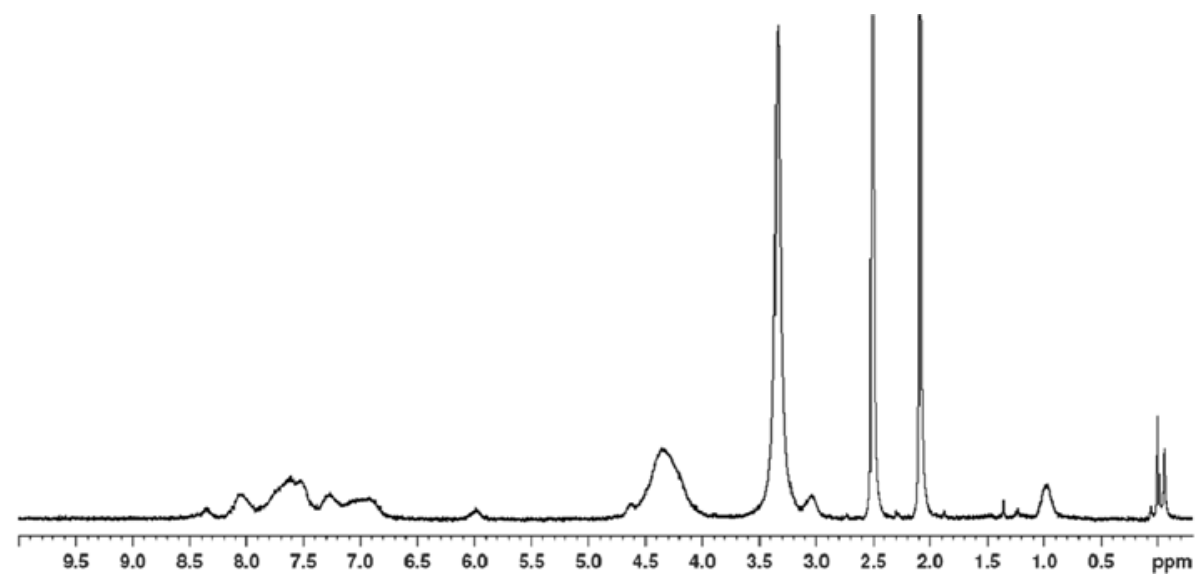

Figure 2. ${ }^{1} \mathrm{H}$ NMR spectrum of polymer 3 in DMSO- $d_{6}$.

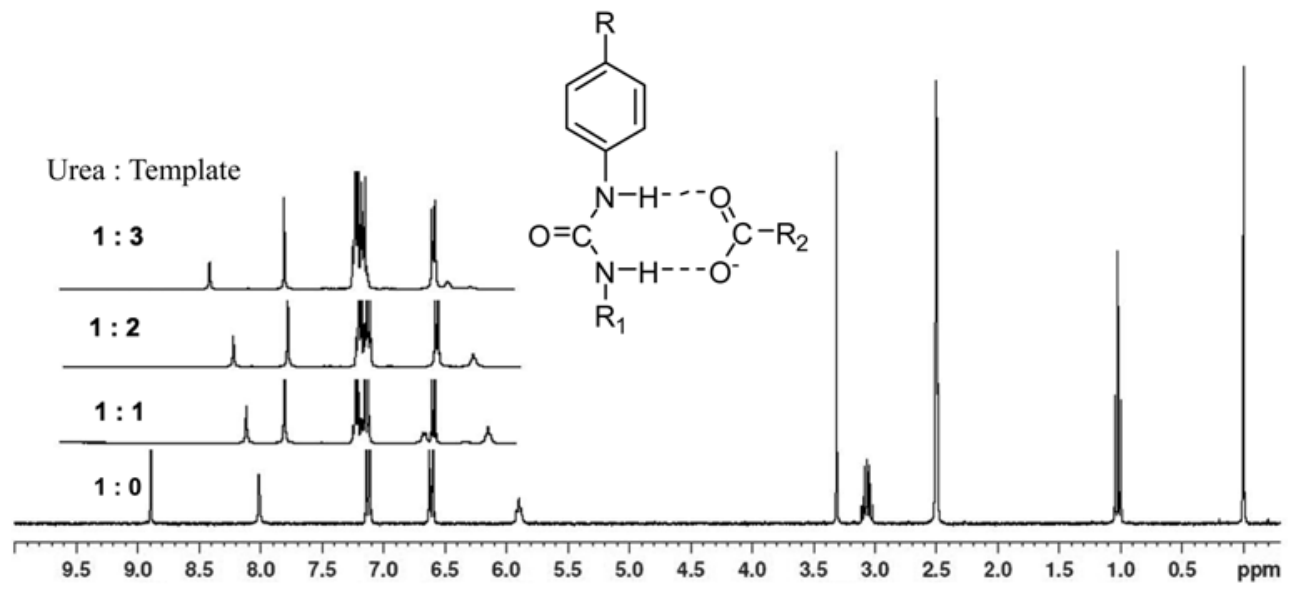

Figure 3. ${ }^{1} \mathrm{H}$ NMR spectra of urea compound 2 and its complexes with Z-Gly-OH in DMSO- $d_{6}$.

shifted gradually downfield and broadened, suggesting the formation of hydrogen bondings between the urea and the template (Figure 3).

Polymer 3 and the template were dissolved in DMF. After stirring $30 \mathrm{~min}$, the polymer solution was cast on a quartz cell and dried under vacuum at $40{ }^{\circ} \mathrm{C}$ for $3 \mathrm{~h}$. The resulting film was irradiated with $365 \mathrm{~nm}$ UV light to yield a yellow thin film with a thickness of about $16 \mu \mathrm{m}$. The polymer film was not soluble in common organic solvents. Figure 4 shows the DSC thermograms of the polymer measured before and after UV irradiation. The $T_{g}$ of the polymer was $-10{ }^{\circ} \mathrm{C}$, which increased to $15^{\circ} \mathrm{C}$ after UV irradiation. We presume that the polymer film was cross-linked by the [2+2] addition reaction of the chalcone units on the polymer chains upon UV irradiation.

The template molecules in the cross-linked polymer film were removed by Soxhlet extraction with methanol in the presence of acetic acid. The control polymer film was prepared in the same manner for the preparation of the imprinted polymer film in the absence of the template and TEA.

Recognition Test for Template. The ability of the molec-

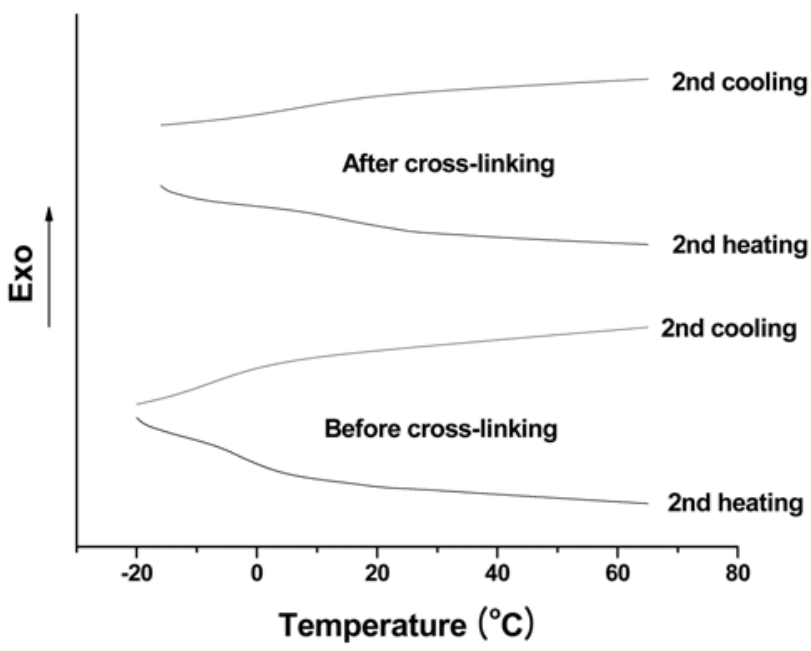

Figure 4. DSC thermograms of polymer 3 measured before and after cross-linking.

ularly imprinted film to recognize the template was investigated. In the rebinding test, the molecularly imprinted and 


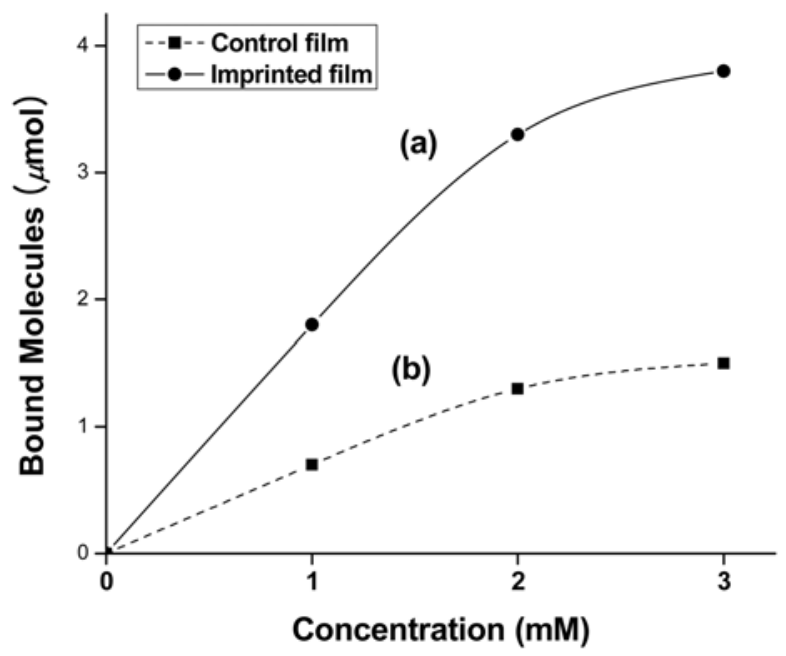

Figure 5. Amounts of bound Z-Gly-OH (a) by the imprinted polymer film and (b) the control film according to the sample concentration.

the control films (20 mg) were added to a solution of Z-Gly$\mathrm{OH}$ (template) in $10 \mathrm{~mL}$ of chloroform at various concentrations $(1,2$ and $3 \mathrm{mM})$. After incubating for $24 \mathrm{~h}$ at room temperature, the polymer films were isolated by filtration. The amount of the template captured by the polymer films was determined by measuring the residual template in the filtrate by reverse phase HPLC. Figure 5 shows the amount of the template bound to the imprinted and the control polymer films according to the sample concentration. The imprinted polymer exhibited much higher recognition ability than the control polymer.

(a)

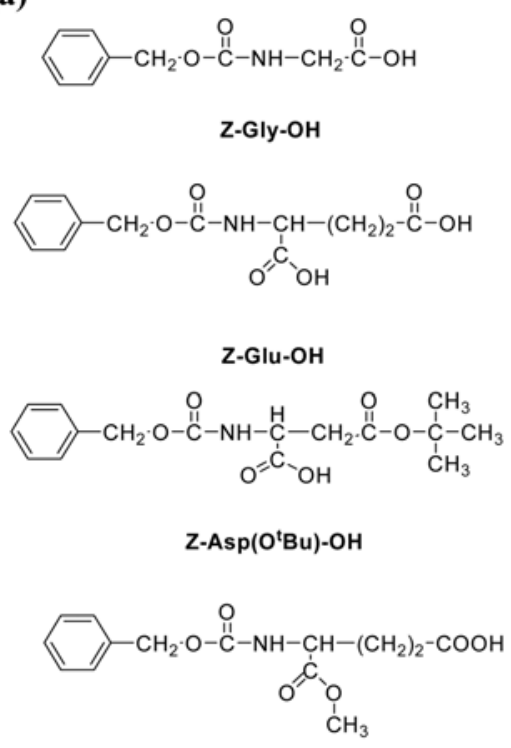

\section{(b)}

Selectivity Test. We also investigated the specific recognition ability of the imprinted polymer for the template and its structural analogues. The rebinding tests were carried out in the same manner as described above. The polymer films $(20 \mathrm{mg})$ were incubated in a solution of an analyte in chloroform $(2 \mathrm{mM})$. The tests were conducted using Z-Glu-OH, $\mathrm{Z}$-Asp $\left(\mathrm{O}^{t} \mathrm{Bu}\right)-\mathrm{OH}$, and $\mathrm{Z}$-Glu-OMe, which are amino acid derivatives. As expected, the imprinted film showed higher specific recognition ability for the template than for its structural analogues (Figure 6). The lowest response for Z$\operatorname{Asp}\left(\mathrm{O}^{t} \mathrm{Bu}\right)-\mathrm{OH}$ was attributed to the fact that the carboxylic acid side group was blocked with a bulky tert-butyl group. These results indicated that template-shaped cavities were formed in the cross-linked polyphosphazene film. The urea group inside the cavity would form a hydrogen bond with the carboxylic acid moiety of the template in the rebinding process.

\section{Conclusions}

We explored the use of a photocross-linkable polyphosphazene for molecular imprinting. We introduced functional urea groups and photoreactive chalcone groups to the phosphazene backbone. The template molecule was complexed with the functional groups on the polymer chains. Owing to the polymeric nature of the complex, we were able to fabricate the complex into a thin film. The molecularly imprinted film with a rigid network structure was obtained by crosslinking reaction between the photoreactive groups on the polymer chains and subsequent extraction of the template molecules.

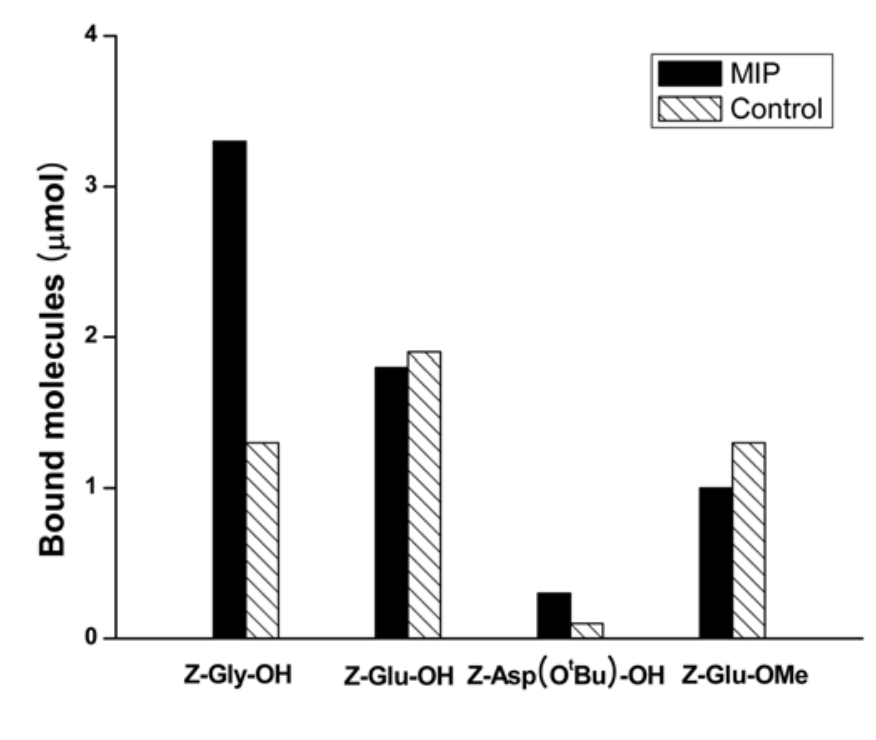

Figure 6. (a) Template molecule and its analogues. (b) Amount of bound molecules by the imprinted film and the control film. All experiments were repeated 3 times. 
Acknowledgement. This work was supported by the Korea Science and Engineering Foundation (R01-2007000-10324-0).

\section{References}

(1) G. Wulff, Chem. Rev., 102, 1 (2002).

(2) K. Haupt and K. Mosbach, Chem. Rev., 100, 2495 (2000).

(3) S. E. Bystrom, A. Borje, and B. Akermark, J. Am. Chem. Soc., 115, 2081 (1993).

(4) K. P. Leung, C. F. Chow, and H. W. Lam, J. Mater. Chem., 11, $2985(2001)$

(5) S. Dai, M. C. Burleigh, Y. S. Shin, C. C. Morrow, C. E. Barnes, and Z. Xue, Angew. Chem. Int. Ed., 38, 1235 (1999).

(6) G. Vlatakis, L. I. Andersson, and K. Mosbach, Nature, 361, 645 (1993).

(7) M. Komiyama, T. Takeuchi, T. Mukawa, and H. Asanuma, Molecular imprinting from fundamentals to applications, WileyVCH, Weinheim, Germany, 2003.

(8) H. Cao, J. B. Xiao, and M. Xu, Macromol. Res., 14, 324 (2006).

(9) C. H. Lim, C. D. Ki, T. H. Kim, and J. Y. Chang, Macromolecules, 37, 6 (2004).
(10) T. H. Kim, C. D. Ki, H. Cho, T. Chang, and J. Y. Chang, Macromolecules, 38, 6423 (2005).

(11) H. R. Allcock, Angew. Chem. Int. Ed., 16, 147 (1977).

(12) H. R. Allcock, R. L. Kugel, and K. J. Valan, Inorg. Chem., 5, 1709 (1966).

(13) H. R. Allcock, Chemistry and Applications of Polyphosphazenes, Wiley-Interscience, Hoboken, NJ, 2003.

(14) A. J. Hall, P. Manesiotis, M. Emgenbroich, M. Quaglia, E. D. Lorenzi, and B. Sellergren, J. Org. Chem., 70, 1732 (2005).

(15) A. J. Hall, M. Quaglia, P. Manesiotis, E. D. Lorenzi, and B. Sellergren, Anal. Chem., 78, 8362 (2005).

(16) J. L. Urraca, M. C. Moreno-Bondi, G. Orellana, B. Sellergren, and A. J. Hall, Anal. Chem., 79, 4915 (2007).

(17) J. Y. Chang, S. W. Nam, C. G. Hong, J. H. Im, J. H. Kim, and M. J. Han, Adv. Mater., 13, 1298 (2001).

(18) G. S. Lim, B. M. Jung, S. J. Lee, H. H. Song, C. Kim, and J. Y. Chang, Chem. Mater, 19, 460 (2007).

(19) S. W. Nam, S. H. Kang, and J. Y. Chang, Macromol. Res., 15, 74 (2007)

(20) S. H. Cho, H. S. Lim, B. K. Jeon, J. M. Ko, J. Y. Lee, and W. G. Kim, Macromol. Res., 16, 31 (2008). 